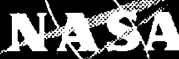

\title{
An Air-Breathing Launch Vehicle Concept for Single-Stage-to-Orbit
}

Charles J. Trefny

Glenn Research Center, Cleveland, Ohio

Prepared for the 35th Joint Propulsion Conference and Exhibit sponsored by the AIAA, ASME, SAE, ASEE Los Angeles, California, June 20-23, 1999

National Aeronautics and Space Administration

Glenn Research Center 


\section{Acknowledgments}

The Trailblazer team at the NASA Glenn Research Center performed the work presented herein. This team includes personnel from the Turbomachinery and Propulsion Systems Division, the Engineering Design and Analysis Division, the Propulsion Systems Analysis Office, the Hypersonics Projects Office, and the Launch Vehicle and the Transportation Projects Office. The Hypersonic Airbreathing Propulsion Branch, and the Systems Analysis Office at the NASA Langley Research Center, and the Advanced Space Transportation Program Office at the NASA Marshall Space Flight Center provided consultation and review. This work is supported by the NASA Propulsion Base Research and Technology Program.

Available from

NASA Center for Aerospace Information

7121 Standard Drive

Hanover, MD 21076

Price Code: A03
National Technical Information Service 5285 Port Royal Road Springfield, VA 22100 


\title{
AN AIR-BREATHING LAUNCH VEHICLE CONCEPT FOR SINGLE-STAGE-TO-ORBIT
}

\author{
Charles J. Trefny* \\ National Aeronautics and Space Administration \\ Glenn Research Center \\ Cleveland, Ohio 44135
}

\begin{abstract}
The "Trailblazer" is a 300 -lb payload, single-stageto-orbit launch vehicle concept that uses air-breathing propulsion to reduce the required propellant fraction. The integration of air-breathing propulsion is done considering performance, structural and volumetric efficiency, complexity, and design risk. The resulting configuration is intended to be viable using near-term materials and structures. The aeropropulsion performance goal for the Trailblazer launch vehicle is an equivalent effective specific impulse $\left(I^{*}\right)$ of $500 \mathrm{sec}$. Preliminary analysis shows that this requires flight in the atmosphere to about Mach 10 , and that the gross lift-off weight is $130,000 \mathrm{lb}$. The Trailblazer configuration and proposed propulsion system operating modes are described. Preliminary performance results are presented. and key technical issues are highlighted. An overview of the proposed program plan is given.
\end{abstract}

\section{Summary}

The Trailblazer is a reusable, single-stage-to-orbit launch vehicle concept, intended to reduce the cost of space access by making optimum use of air-breathing propulsion. The Trailblazer development program is based on maturation of a 300 -lb payload reference vehicle to a point at which commercial development could proceed. The propulsion system operates in four modes including ramjet, scramjet, and rocket modes from lift-off to orbit. A new low speed mode, intended to minimize weight and complexity is proposed.

Preliminary analysis of the conceptual design indicates that the inlet capture area is sufficient for air-breathing acceleration to Mach 10, resulting in a required

*Senior Member-AIAA. propellant mass fraction of 78.4 percent and an overall oxidizer-to-fuel mass ratio of 2.80 . Based on preliminary structural modeling, the gross lift-offweight is $130,000 \mathrm{lb}$. Numerous technical issues are being addressed in a propulsion technology maturation program.

\section{Introduction}

A long-term NASA goal is to reduce the cost of space access. One means of achieving this goal is to develop reusable launch vehicles. Single-stage-to-orbit (SSTO) vehicles are one class in a larger group of concepts under consideration. NASA's X-33 program will provide information on the near-term viability of SSTO rockets, and the use of advanced, lightweight materials in launch vehicle structures. The present work will advance the understanding of the use of airbreathing propulsion. Air-breathing propulsion reduces the propellant fraction required for SSTO. However, the overall benefit in terms of SSTO feasibility, design margin, and cost reduction will depend on weight, and complexity. Engineering design, fabrication, and demonstration is required to accurately evaluate these factors. Therefore, emphasis is placed on the engineering of a particular concept called "Trailblazer" (Fig. 1), that has good potential for structural efficiency, and minimum complexity. Trailblazer is intended to make optimum use of air-breathing propulsion for the acceleration to orbit mission.

The proposed program (Fig. 2) is based on maturation of the Trailblazer "reference vehicle" design to a point at which commercial development could begin. The design will evolve based on results from a propulsion technology maturation program, and a flight demonstration. The propulsion technology maturation consists of complementary experimental, numerical, 
and analytical efforts. Planned experiments range from proof-of-concept and component development tests, to flight-like propulsion system tests. CFD analysis is used to guide component and test rig design, estimate performance, and analyze experimental results. The purpose of flight demonstration is to validate performance and structural weight estimates, and drive all manufacturing and operational issues to resolution.

The purpose of this paper is to introduce the Trailblazer reference vehicle conceptual design, and the rationale behind configuration choices. The propulsion configuration and thermodynamic cycles will be described. Preliminary system performance results will be presented and technical issues highlighted.

\section{Symbols}

D Total drag force including all surfaces not accounted for in the net thrust. Acts in direction of flight.

g. Proportionality constant, $32.174 \mathrm{lb} / \mathrm{ft} / 1 \mathrm{~b}_{\mathrm{r}}-\sec ^{2}$

$\mathrm{H}$ Altitude

$l_{\text {eil }}$ Effective specific impulse. The sum of all forces acting on a flight vehicle in the direction of flight, divided by the propellant flow rate

$I_{\text {net }}$ Specific impulse based on net thrust

$I_{v * k}$ Specific impulse based on vacuum thrust in rocket mode (mode IV)

I* Equivalent, effective specific impulse. The constant value of specific impulse that, when used in the rocket equation, results in the correct mass ratio for a launch vehicle with variable effective specific impulse

L Aerodynamic lift force acting in direction normal to llight path

$\mathbf{M}_{0}$ Free-stream Mach number

P. Rocket chamber pressure

ฯ. Free-stream dynamic pressure

T Net axial thrust force. Based on a control volume defined by the captured airstream and nacelle surfaces, extending from the inlet spike leading edges to the vehicle trailing edge. Forward-facing nacelle and boundary-layer diverter surfaces are accounted for in the net thrust.

$\Delta V$ Change in velocity

W Instantaneous vehicle weight

$\mathrm{W}_{n}$ Inert mass fraction, vehicle weight at lift-off minus payload and ascent propellant

$\alpha \quad$ Angle of attack

$\gamma \quad$ Angle between flight path and Earth's surface.

\section{$\underline{\text { System Performance Goals }}$}

The equivalent, effective specific impulse ( $\left.I^{*}\right)$ is used herein as a measure of "aeropropulsion" performance. A brief explanation of I* follows; a complete derivation can be found in Ref. 1 . The effective specific impulse $\left(I_{\text {eff }}\right)$ is defined as the sum of all forces in the direction of flight due to propulsion, aerodynamics and gravity, divided by the propellant flow rate. $I_{\text {uff }}$ for an air-breathing launch vehicle can vary by an order of magnitude during ascent, rendering its use in the traditional rocket equation invalid. $I^{*}$ is the constant, "equivalent" value of $I_{\text {eff }}$ that, when used in the rocket equation, results in the correct mass ratio. I* therefore represents the efficiency at which a launch vehicle expends its propellant to achieve a given velocity.

Figure 3 shows the effect of $\mathrm{I}^{*}$ on the propellant fraction required (PFR) to achieve SSTO. At I* values approaching the maximum theoretically possible for chemical rockets, the PFR to achieve SSTO is about 90 percent of the gross lift-off weight (GLOW). The development of an SSTO rocket thus depends on reducing the inert mass fraction to about 10 percent. Launch cost reduction depends on reusability of which SSTO is only one component. Another is increased design margin, which is in conflict with the requirement for minimum inert mass. The prospect of an air-breathing launch vehicle provides a means of increasing I* well beyond that of chemical rockets. The associated reduction in propellant fraction does not, however, guarantee SSTO closure at a practical GLOW, increased margin for reusability, or reduced operations and maintenance costs. Mitigating factors must be considered. These include the weight and complexity of air-breathing components, the burden of flight within the atmosphere (heating, drag, and structural loading), and a lower propellant bulk density (due to the exclusive use of hydrogen in air-breathing 
modes) that tends to increase tank weight an aerodynamic drag. A systems approach to air-breathing launch vehicle design is required due to the interrelationship of these factors with aeropropulsion performance.

The net benefit of higher $I^{*}$ depends on the degree to which the mitigating factors deplete the structural margin afforded by increased aeropropulsion performance. This is depicted in Fig. 4 where the inert mass fraction is plotted as a function of $I^{*}$ for various payload fractions. A net system benefit can result only if the vector sum shown tends toward increasing margin. The Trailblazer program will determine whether or not the application of near-term airbreathing propulsion technology to an SSTO launch vehicle will result in sufficient margin and reusability to warrant commercial development. The goal for initial demonstration has been set at $I^{*}$ equal to $500 \mathrm{sec}$, and an inert mass fraction of 20 percent ( 1 percent payload fraction). These values are less than that theoretically possible on both the aeropropulsion and structural weight axes of Fig. 4, but may represent a nearer-term, more practical solution to cost reduction than the SSTO rocket, and higher performance airbreathing concepts such as the National Acro-Space Plane (NASP). ${ }^{2}$ This target represents the least risk, and leaves room for evolution with subsequent advances in propulsion, materials, and actively-cooled structures.

\section{Trailblazer Reference Vehicle Conceptual Design}

The Trailblazer conceptual design philosophy is to take optimum advantage of air-breathing propulsion performance. That is, not to exceed the point of diminishing returns on increasing $\mathrm{I}^{*}$. The basic configuration and operational scheme has been constrained to provide high potential for lightweight, durable structures and tanks, and to minimize risk and complexity. Axisymmetric geometry provides inherent structural efficiency, and lower uncertainty in aerodynamic and structural design, leading to a reduction in required factors of safety.

\section{Design Requirements}

The basic configuration and operational schemes were chosen to provide good contrast to prior airbreathing launch vehicle concepts such as the NASP. It is required that the vehicle be SSTO and reusable. The number of missions is not yet defined. Vertical lift-off and horizontal landing are proposed to minimize wing structure and landing gear weight. This also minimizes reliance on aerodynamics at low speed, which can drive horizontal take-off systems to non-optimum structural shapes. Vertical lift-off also eliminates many safety issues associated with high-speed taxi. The propellants are liquid oxygen (LOX) and liquid hydrogen $\left(\mathrm{LH}_{2}\right)$. The energy per unit mass and heat capacity of hydrogen were deemed necessary. Finally, the reference vehicle is designed to carry $300 \mathrm{lb}$ to low-Earth orbit. This is to minimize the scale and cost of a relevant demonstration vehicle. The design requirements allow subsequent scaling to larger payloads without regard to runway length or weight restrictions.

Vehicle Configuration and Propulsion Integration

The basic vehicle configuration is pictured in Fig. 5. The dimensions shown are preliminary and correspond to a GLOW of $130,000 \mathrm{lb}$. Three semicircular propulsion pods are mounted symmetrically at $120^{\circ}$ intervals around the periphery of the vehicle's circular cross section. This arrangement provides for diversion of the forebody boundary layer and results in an axial total thrust vector. The forebody is parabolic with a $10^{\circ}$ half-angle nose. This shape was chosen for high structural and volumetric efficiency and for low drag without regard for inlet precompression. The inlet spikes are offset from the forebody surface on boundary-layer diverter pylons. As the conceptual design evolved, the required tank volumes and propulsion system length placed the leading edge of the diverters forward of the tangency point on the parabolic forebody. The aft-facing projected area of the vehicle is used for nozzle expansion, resulting in an exit-tocapture area ratio of $2.78: 1$. At low speed, this integration is intended to provide an altitudecompensating effect, similar to that of a plug nozzle, that minimizes over-expansion losses. The wings are sized such that the total planform generates sufficient lift to support the vehicle at a maximum angle-of-attack of $6^{\circ}$ in air-breathing modes.

The aeropropulsion performance of the vehicle is strongly dependent on the inlet capture area. The maximum viable air-breathing Mach number and $I_{c f t}$ are functions of air capture. The optimum capture area cannot be determined, however, until the structural weight and thermal protection characteristics of both the vehicle and propulsion system are better understood. The current total capture area of $98.41 \mathrm{ft}^{2}$ (69.3 percent of the forebody maximum cross-sectional area) is sized for a maximum air-breathing Mach number of about 10 .

Although the forebody is not intended to be a compression surface, flow-ficld calculations ${ }^{3}$ have revealed that significant compression does persist to the diverter leading edge station resulting in significantly 
greater mass capture than that of a free stream inlet. At Mach 10, the static pressure (stream-thrust averaged over the cross section of the captured stream) is twice that in the free stream, at a contraction ratio of about 1.5 .

The inlets must operate when the vehicle is at an angle-of-attack. Three-dimensional, turbulent, Parabolized Navier-Stokes calculations have been performed on the forebody shape at Mach numbers from 1.2 to 10 , and angles-of-attack of $0^{\circ}, 3^{\circ}, 6^{\circ}$, and $9^{\circ}$. These solutions indicate that the flow field at the spike leading edge plane is free of severe distortions when the angle-of-attack is less than or equal to $6^{\circ}$. Isolated, axisymmetric mixed-compression inlets have been operated at angles-of-attack greater than $7^{\circ} .4$ Additional numerical and experimental modeling will be required to determine the exact operating limits of the present configuration, which is in close proximity to the forebody.

The vehicle cross section (Fig. 6) reveals the size and location of the propellant tanks. These are sized to accommodate the relative volumes of $\mathrm{LOX}$ and $\mathrm{LH}_{2}$ required. The LOX tank was placed forward of the $\mathrm{LH}_{2}$ tank to increase longitudinal static stability. However, this is not the preferred arrangement for minimum structural weight. Other more optimum arrangements may be possible once stability requirements are better understood.

\section{Propulsion System Description}

Figure 7 is a cut-away view of a propulsion "pod," Its axisymmetric design provides the potential for good structural efficiency and minimizes aerodynamic design and analysis uncertainty due to the two-dimensional nature of the flow field. The axis of symmetry is a line parallel to the vehicle axis at a distance equal to the diverter radius from vehicle axis.

Inlet. The inlet is of translating-centerbody, mixedcompression design. Centerbody translation allows starting, provides variable contraction ratio, and closes off the duct for rocket-mode operation. This configuration has minimum sealing, support, and actuation issues. At full retraction, the spike and diverter planforms are coincident. When extended, the edges of the spike overhang the diverter pylon. The inlet duct cross-section is semi-annular. It is not strictly axisymmetric though, since the cylindrical surface upon which the annulus terminates is not a radial plane of symmetry. A step in the centerbody contour at the throat is intended to provide a degree of inlet isolation, and a surface for axial fuel injection at high flight Mach numbers. It is also the point at which the centerbody contacts the cowl contour. The current geometry results in a contraction ratio of 15 with shock-on-lip at Mach 6. Inlet contours and performance estimates based on axisymmetric, turbulent, Navier-Stokes calculations are presented in Ref. 3. The throat is angled toward the inlet axis at $15^{\circ}$ to reduce the length, weight and wetted area of this portion of the flow path. The $12^{\circ}$ spike angle is also meant to minimize length. The maximum spike and throat angles for acceptable inlet aerodynamic operability without boundary layer bleed is one of the key inlet design issues. The incorporation of a boundary-layer bleed system is to be avoided due to the weight and complexity of the associated ducting, metering, and control systems.

Rocket Element. There is one rocket element per flow path, located in a semi-circular hub that is fixed with respect to the vehicle. The centerbody translates over the hub, and their trailing edges are coincident when the centerbody is in its aft-most position. The total duct cross-sectional area at the hub trailing edge station is 0.4 times the inlet capture area. The rocket element operates at a constant oxidizer-to-fuel mass ratio $(\mathrm{O} / \mathrm{F})$ and variable chamber pressure.

The $\mathrm{O} / \mathrm{F}$ ratio must be optimized during reference vehicle maturation, considering rocket $I_{s p}$, and propellant density, which affects vehicle weight and drag. A baseline value of 6 has been used in the present analysis. A maximum chamber pressure of 1500 psia was chosen as a baseline value to be optimized during definition of the propellant cycle and cooling circuit design. The throat area is 0.0068 times the inlet capture area which results in a lift-off thrust-to-weight ratio of about 1.7 for a $130,000 \mathrm{lb}$ GLOW. The rocket element expansion ratio is 10 , constrained by the available hub cross section, which is 8.5 percent of the inlet capture area. The hub cross section must not be excessive because it acts as a base area within the flow path when the rocket is not operating.

The rocket element's plug nozzle configuration provides pressure compensation as the rocket is throttled and ram pressure increases during low speed propulsion mode. Its semi-circular cross-section also integrates well with the semi-circular hub base. It is designed with 50 percent internal expansion to allow throttling to approximately 20 percent of maximum thrust. There are numerous issues with throttling and cooling of annular rockets that are currently being addressed. The performance increments gained by rocket throttling may be outweighed by increases in weight and complexity. 
Ramjet Duct and Nozzle. Aft of the rocket element, a conical cowl surface extends downstream at a $5.67^{\circ}$ wall angle until intersected by a $15^{\circ}$ half-angle "expansion cone." The surface of this virtual expansion cone defines the trailing edge geometry of the cowl and vehicle surfaces. The expansion cone apex is located such that the maximum internal area of the flow path is 1.25 times the inlet capture area, and the distance between the hub and this area is 2.85 times the cowl lip radius. The maximum cross-sectional area is sized to accommodate stoichiometric combustion of the expected airstream at low supersonic flight Mach numbers. The duct length must be sufficient for completion of the ramjet combustion process. These are baseline values and will be revised as higher fidelity analysis and test data become available. This crude method of generating the nozzle contour will also be revisited. It does, however, illustrate desirable integration and altitude-compensation features. The total area ratio from the rocket element throat to the vehicle aft projected area is $409: 1$.

Propellant System. Conceptual design of a powerbalanced propellant delivery system including turbopumps, valves, heat exchangers (actively cooled surfaces) and associated piping and controls is in progress. Various propellant cycles will be examined to determine those best suited to the present application. Some factors to be considered are the large areas of actively cooled surface that will lead to high pressure drops, and may require more fuel for cooling than that required for combustion in air-breathing modes. Also, independent control of fuel and oxidizer flow rates is required in the various propulsion modes described below.

\section{Propulsion System Operating Modes}

The Trailblazer propulsion system operates in four distinct modes during the earth-to-orbit ascent. The flow path is designed to accommodate the thermodynamic process of each.

\section{Mode I-Lift-off and Low Speed}

This mode, depicted in Fig. 8(a) provides the high thrust required for lift-off, and initiates the high specific impulse ramjet cycle. The rocket and air streams interact along a matched-pressure boundary but are not intended to mix. This mode of operation has been dubbed the independent ramjet stream (IRS) cycle. Traditional ejector-ramjet cycles have slightly higher thermodynamic performance, but would require mixing enhancement devices or multiple rocket chambers to shorten the length of duct required for mixing. This increases complexity and may have an adverse effect on other modes of operation.

At lift-off, the rocket operates at maximum chamber pressure. The inlet centerbody is fully extended. The open inlet ventilates the ramjet duct preventing over-expansion of the rocket. As the vehicle gains speed, the airstream can be fueled and burned to generate ramjet thrust. As the proportion of ramjet thrust becomes significant, the rocket chamber pressure can be reduced and optimized for maximum $I_{\text {err }}$ The high thrust rocket cycle gives way to the high specific impulse ramjet cycle in this manner. When ramjet thrust alone is sufficient, the rocket is shut off completely, defining the transition to mode II.

A two-stream, one-dimensional model of this cycle has been developed to determine the optimum ramjet fuel-air ratio and thermal throat location for a given flight Mach number and rocket chamber pressure. Performance maps generated using this procedure then allow the rocket chamber pressure to be varied during trajectory optimization for maximum I*.

Combustion of the airstream and the resulting thermal throat must occur at a cross-sectional area on the order of the inlet capture area to avoid sub-critical operation of the inlet and associated spillage drag. One method to accomplish this is the use of in-stream spray bars such as those reported in Refs. 7 to 9. Spray bars are impractical for the present problem however, because they would have to be retracted during operation in modes III and IV to avoid severe expansion process losses and cooling problems. The present approach is to use fuel injectors in the annular inlet diffuser to distribute fuel in the airstream. The premixed stream is then ignited by its confluence with the rocket, and the combustion process proceeds downstream to completion at a large cross-sectional area. Fuel is distributed in the annulus such that thin, noncombustible layers exist at the walls to prevent flashback. Some mixing between the rocket stream and this "buffer layer" must then occur for ignition to proceed.

Peak performance is obtained with the thermal throat at a specified cross-sectional area that varies with flight Mach number. The axial location and therefore cross-sectional area of the thermal throat depends on the point of ignition and the rate at which the flame travels across the duct. The radial distribution of fuel can therefore be used to control thermal throat location based on pressure sensed at specific locations in the inlet. 
There are a number of issues associated with this scheme that are currently under investigation. The twodimensional features of flame propagation into a thermally-choking stream are unknown. Auxiliary flame-holding sites may be required to avoid an excessively long duct. Whether or not sufficient control of the thermal throat location is possible must be determined. The prevention of premature combustion due to flashback must be assured, especially in the presence of realistic inlet flow distortions. Should the present scheme prove infeasible, a retractable spray bar arrangement could be considered. Another option is to revert to the simultaneous mixing and combustion cycle, described in Ref. 5, where the airstream is fueled by mixing with fuel-rich rocket effluent. In this cycle, the thermal throat location could be modulated by active control of mixing intensity. Multiple rocket chambers, or mixing enhancement devices, would likely be required to avoid excessive duct length.

\section{Mode II-Thermal-Throat Ramjet}

When sufficient ramjet thrust is available, the rocket is shut off. The started inlet requires a specified exit pressure for optimum performance. As in mode I, this requires control of the thermal throat location. If the transition Mach number is below about 2.5, a fuel distribution and combustion process similar to that used in mode I would be required, except that piloting would be from the recirculation zone formed downstream of the rocket hub. Some form of auxiliary piloting may also be required. As the free stream stagnation temperature increases, auto-ignition and flashback to the point of injection would be unavoidable. However, the required thermal throat cross-section is also reduced so that the mixing-limited combustion process pictured in Fig. $8(\mathrm{~b})$ is feasible. Fuel injection from the walls at various axial stations is used to control the thermal throat location. The Mach number at which the mixinglimited ramjet combustion process is feasible has not yet been determined. Techniques for piloting the premixed combustion process and controlling the thermal throat location must be examined.

\section{Mode III-Supersonic Combustion Ramjet}

Between approximately Mach 5 and 6 , the combination of inlet losses, high duct pressure, cooling requirements, and non-equilibrium chemistry make transition to the supersonic combustion mode beneficial. Fuel is injected axially from the centerbody step, and at various downstream stations, to tailor the combustion distribution for optimum performance and avoid choking. The inlet contraction ratio can be optimized as information on weight and cooling becomes available.
The issues associated with mode III are those generally associated with scramjet propulsion (see Ref. 10). In addition, the nozzle contours are non-ideal due to the multimode nature of the flow path. The effective specific impulse is very sensitive to the expansion process efficiency, especially approaching the expected maximum air-breathing Mach number of about 10 .

\section{Mode IV-Rocket}

Scramjet thrust per unit airflow decreases with flight Mach number. As $I_{\text {efi }}$ approaches that of the rocket vacuum specific impulse $\left(\mathrm{I}_{\mathrm{vx}}\right)$ or the flight Mach number approaches a constraint based on system considerations, transition to mode IV occurs. The transition sequence begins as the vehicle pitches up, and climbs to a minimum dynamic pressure of about 500 psfa at constant Mach number. The centerbody is then translated aft to close off the air-breathing flow path and the rocket is reignited (Fig. 8(c)).

The potential for high performance exists due to the large area ratio from the rocket throat to the vehicle aft-projected area. The area distribution is not ideal, however, with a significant gap between the rocket exit area and the air-breathing duct. This "free-expansion" must be managed by pressurizing the cavity upstream of the rocket with a small amount of bleed flow. The efficiency of this type of process has been studied parametrically for axisymmetric geometries in Ref. 11. The sensitivity of $I^{*}$ to mode IV performance is high, roughly $0.7 \mathrm{sec}$ of $\mathrm{I}^{*}$ per $\mathrm{sec}$ of $\mathrm{I}_{\mathrm{vw}}$, since about 60 percent of the total velocity is imparted to the vehicle in this mode. Uncertainty in $I_{v * x}$ must be minimal. Three-dimensional modeling of the expansion process is required. The rocket must be throttled in mode IV if a maximum acceleration constraint is imposed.

To protect the cowl lips during reentry, inert gas would be bled into the forward cavity as pictured in Fig. 8(d).

\section{Analysis}

\section{Trajectory Optimization}

The aeropropulsion performance of the reference vehicle is determined by trajectory optimization using the Optimal Trajectories by Implicit Simulation (OTIS) $^{12}$ program. Inputs to OTIS include propulsion performance, configuration aerodynamics, various constraints, and the required orbit. OTIS determines the trajectory that maximizes the final weight and therefore I*. This does not necessarily represent the system 
optimum though. Trajectory optimization is part of an iterative process that accounts for the effects of the various constraints on structural weight.

Mode I propulsion performance was calculated using the method of Ref. 6 . Net thrust and propellant flow rates were determined as functions of free stream Mach number and rocket chamber pressure. The optimum schedule of rocket chamber pressure is determined concurrently with the optimum trajectory. Performance in modes II and III was calculated using the Ramjet Performance Analysis (RJPA) program." Inlet recovery and drags for all air-breathing modes were based on the 2-D axisymmetric calculations described in Ref. 3. The mode IV $I_{\text {s: }}$ was estimated to be $450 \mathrm{sec}$ using the method of Ref. 11. An atmospheric back-pressure term is subtracted from the resultant thrust. The aerodynamic characteristics of the vehicle as functions of Mach number and angle-ofattack were evaluated using the Aerodynamic Preliminary Analysis System ${ }^{14}$ (APAS).

The constraints listed in Table I were imposed during trajectory optimization. The maximum dynamic pressure and mode III to IV transition Mach number constraints will be revisited once the sensitivity of vehicle weight to these parameters is understood. An easterly, vertical launch from $28.5^{\circ}$ latitude, to a $220 \mathrm{nmi}$ circular orbit was assumed.

A summary of key points along the optimum trajectory is presented in Table II. Time spent in atmospheric flight in air-breathing propulsion modes is less than $6 \mathrm{~min}$. Therefore, thermal protection, and cooling system designs must be based on transient heating analysis. Total elapsed time from lift-off to orbit is $39 \mathrm{~min}, 48 \mathrm{sec}$. The final mass in orbit is 21.6 percent of the GLOW (78.4 percent PFR). I* for this trajectory is $509.3 \mathrm{sec}$, based on the initial and final vehicle weight, and the total change in inertial velocity due to propulsion. The overall vehicle $\mathrm{O} / \mathrm{F}$ for this trajectory is 2.80 .

The optimum trajectory appears in Fig. 9. It is characterized by flight at maximum dynamic pressure to the maximum air-breathing Mach number of 10 . At this point, the vehicle climbs to the minimum dynamic pressure of $500 \mathrm{psfa}$, transitions to mode IV, then follows a higher altitude path more optimum for rocket propulsion. The remaining mode IV powered phase, coast phase, and circularization burn are not shown in the figure. The optimum chamber pressure (Fig. 10) is the maximum from lift-off through the transonic drag rise, followed by a sharp reduction as higher efficiency ramjet thrust becomes available. Full transition to ramjet mode occurs at Mach 2.04. The minimum Mach number at which this transition can occur depends on air capture (both inlet area, and inlet mass flow ratio). The effect of increasing the constrained minimum chamber pressure is being evaluated in light of the additional complexity introduced by deep throttling. To satisfy the $4 \mathrm{~g}$ maximum acceleration constraint, it is necessary to throttle the rocket to $625 \mathrm{psia}$ in mode IV. The vehicle angle-of attack and lift-1o-drag ratio along the optimum trajectory appear in Fig. 11. Just after liftoff, a pitch-over maneuver initiates transition to the more horizontal flight path required for air-breathing flight. The angle-of-attack peaks at just over $4^{\circ}$ after an initial $25^{\circ}$ negative spike. The angle-of attack remains below $4^{\circ}$ from pitch-over to Mach 10 , when the $6^{\circ}$ constraint is met during the climb prior to transition to mode IV. The vehicle thrust-to-weight ratio, and flightpath angle on the optimum trajectory are shown in Fig. 12. The pitch-over, and transition to nearly horizontal flight are evident in the flightpath angle trace. The thrust-to-weight ratio trace indicates that the acceleration remains well below the $4 \mathrm{~g}$ limit throughout modes I to III. However, rocket throttling is required in mode 4 to remain within the acceleration constraint. The net propulsive specific impulse is shown in Fig. 14, along with the effective specific impulse. The difference between the two curves represents the retarding forces of vehicle drag and gravity. Transition from mode I to II is marked by a sharp increase in $I_{\text {et }}$ as the rocket is shut off. Transition from mode III to IV occurs at Mach 10 as constrained, although the net thrust is sufficient for continued acceleration in mode III ( $I_{c i f}$ is greater than that of mode IV). This potential for higher $I^{*}$ must be carefully traded against reduced propellant bulk density and increased heat load.

\section{Preliminary Closure Results}

The trajectory shown in Fig. 9 defines the thermal, and mechanical loads, the propellant fraction required, and relative size of the propellant tanks. Structural design and optimization based on these inputs is in progress. Scaling of a preliminary structural weight model indicates that the vehicle propellant fraction equals that required (the vehicle is "closed") at a gross lift-off weight of about $130,000 \mathrm{lb}$. The inert mass fraction is slightly greater than the target value of 20 percent resulting in a payload fraction of 0.23 percent.

Preliminary structural weight modeling is based on nonintegral, graphite-epoxy composite propellant tanks that account for about 7 percent of the dry weight. 
Actively-cooled carbon-carbon, and carbon-siliconcarbide composites were assumed for propulsion system surfaces with titanium and aluminum-lithium substructures. Construction techniques and compatibility issues are being addressed. The propulsion system weight is about 39 percent of the dry weight. The vehicle aeroshell and wing structures consist largely of carbon-carbon sandwich panels with halfnium-carbide coating and make up about 30 percent of the dry weight. Allowances were made for regions requiring active-cooling or additional passive thermal protection. The use of halfnium-diboride is being studied for tip and leading edge areas.

The center-of-gravity has been calculated as a function of the amounts of $\mathrm{LOX}$ and $\mathrm{LH}_{2}$ remaining, using a mass distribution based on the preliminary model. The vehicle is statically stable in the pitch axis during ascent, but requires some form of pitch control for trim. Combinations of elevon deflection, differential throttling, and angle-of-incidence are currently being studied. With empty propellant tanks, the center of gravity moves aft and the configuration exhibits neutral static stability. Active pitch control may be required for landing.

\section{Concluding Remarks}

A configuration with potential for structural efficiency and simplicity can meet the 500 sec I* aeropropulsion performance goal with a maximum airbreathing Mach number of about 10. The inlet capture area required for acceleration to Mach 10 is not prohibitive even though the forebody is not optimized for air-capture. The vehicle $\mathrm{O} / \mathrm{F}$ is 2.80 under the cycle performance assumptions stated, which include the IRS low-speed cycle, and a rocket $I_{\text {vix }}$ of $450 \mathrm{sec}$. The vehicle aerodynamics provide sufficient lift at less than $6^{\circ}$ angle-of-attack during air-breathing modes. Based on preliminary structural architecture and weight modeling. the GLOW is $130,000 \mathrm{lb}$.

These preliminary results warrant continued maturation of the reference vehicle concept. Current plans call for more detailed design of the propulsion system including actively cooled composite structures and propellant delivery systems, to refine weight estimates, and assess complexity and cost savings potential. System trades on a number of parameters, such as rocket $\mathrm{O} / \mathrm{F}$ ratio and chamber pressure, maximum air-breathing Mach number, maximum dynamic pressure. inlet capture area, and material selection await more detailed weight modeling.
Ultimately, a multidisciplinary optimization, such as that presented in Ref. 15 could be performed. The inter-relationship between aeropropulsion performance, structural weight and complexity dictates that the entire launch vehicle system is considered during conceptual design.

A series of propulsion component test rigs are currently under development. These will address the operability issues discussed herein, and provide performance validation. Numerous numerical and analytical studies are also in progress to optimize, and increase the fidelity of the reference vehicle design.

\section{Acknowledgments}

The Trailblazer team at the NASA Glenn Research Center performed the work presented herein. This team includes personnel from the Turbomachinery and Propulsion Systems Division, the Engineering Design and Analysis Division, the Propulsion Systems Analysis Office, the Hypersonics Projects Office, and the Launch Vehicle and the Transportation Projects Office. The Hypersonic Airbreathing Propulsion Branch, and the Systems Analysis Office at the NASA Langley Research Center, and the Advanced Space Transportation Program Office at the NASA Marshall Space Flight Center provided consultation and review. This work is supported by the NASA Propulsion Base Research and Technology Program.

\section{References}

1. Escher, W.J.D.; Hyde, E.H.; and Anderson, D.M.: A User's Primer for Comparative Assessments of All-Rocket and Rocket-Based Combined-Cycle Systems for Advanced Earth-to-Orbit Space Transportation Applications. AIAA Paper 95-2474, July 1995.

2. Barthelemy, R.R.: The National Aero-Space Plane Program. AIAA Paper 89-5053, July 1989.

3. DeBonis, J.R.; Trefny, C.J.; and Steffen, C.J.: Inlet Development for a Rocket Based Combined Cycle, Single Stage to Orbit Vehicle Using Computational Fluid Dynamics. AIAA Paper 99-2239, June 1999.

4. Choby, D.A.: Tolerance of Mach 2.50 Axisymmetric Mixed-Compression Inlets to Upstream Flow Variations. NASA TM X-2433, January 1972. 
5. Billig, F.S.: The Integration of the Rocket with the Ram-Scramjet as a Viable Transatmospheric Accelerator. $11^{\text {th }}$ International Symposium on Air-Breathing Engines, Paper 93-7017, September 1993.

6. Yungster, S.; Trefny, C.J.: Analysis of a New Rocket-Based Combined-Cycle Engine Concept at Low Speed. AIAA Paper 99-2393, June 1999.

7. Kerslake, W.R.: Combustion of Gaseous Hydrogen at Low Pressures in a $35^{\circ}$ Sector of a 28-inch-Diameter Ramjet Combustor. NACA RM E58A21a, April 1958.

8. Krull, G.H.; and Burley, R.R.: Effect of Burner Design Variables on Performance of 16-inchDiameter Ram-Jet Combustor Using GaseousHydrogen Fuel. NACA RM E56J08, January 1957.

9. Cervenka, A.J.; and Sheldon, J.W.: Method for Shortening Ram-Jet Engines by Burning Hydrogen Fuel in the Subsonic Diffuser. NACA RM E56G27, October 1956.

10. Heiser, WH.; and Pratt, DT.: Hypersonic Airbreathing Propulsion. American Institute of Aeronautics and Astronautics, Washington D.C. 1994.
11. Smith, T.D.; Steffen, C.J.; Yungster, S.; and Keller, D.J.: Performance of an Axisymmetric Rocket Based Combined Cycle Engine During Rocket Only Operation Using Linear Regression Analysis. NASA TM-1998-206632, March 1998.

12. Hargraves, C.R.; and Paris, S.W.: Direct Trajectory Optimization Using Nonlinear Programming and Collocation. Journal of Guidance, Vol. 10, No. 4, July-August 1987.

13. Pandolfini, P.P.; and Friedman, M.A.: Instructions for Using Ramjet Performance Analysis (RJPA) IBM-PC Version 1.24. The Johns Hopkins University Applied Physics Laboratory, JHU/APL AL-92-P175, June 1992.

14. Cruz, C.I.; and Willhite, A.W.: Prediction of High-Speed Aerodynamic Characteristics Using the Aerodynamic Preliminary Analysis System (APAS). AIAA Paper 89-2173, July 1989.

15. Olds, John R.: Results of a Rocket-Based Combined-Cycle SSTO Design Using Parametric MDO Methods. SAE Paper 941165, April 1994.

TABLE 1.-TRAJECTORY OPTIMIZATION CONSTRAINTS

\begin{tabular}{|l|l|c|c|}
\hline \multicolumn{1}{|c|}{ Parameter } & \multicolumn{1}{|c|}{ Enforced } & $\begin{array}{c}\text { Minimum } \\
\text { value }\end{array}$ & $\begin{array}{c}\text { Maximum } \\
\text { value }\end{array}$ \\
\hline Free stream dynamic pressure (psfa) & All modes & 500 & 1500 \\
\hline Angle-of-attack (deg) & Modes II, III & -6 & +6 \\
\hline Rocket chamber pressure (psia) & Modes I, IV & 300 & 1500 \\
\hline Total acceleration (g`s) & All modes & - & 4 \\
\hline Mode III-IV transition Mach number & Mode III & - & 10 \\
\hline
\end{tabular}

TABLE II-TRAJECTORY SUMMARY

\begin{tabular}{|c|c|c|c|c|c|c|}
\hline Event & $\begin{array}{l}\text { Elapsed } \\
\text { time. } \\
\text { min:sec }\end{array}$ & Altitude & $\begin{array}{l}\text { Inertial } \\
\text { velocity. } \\
\text { fusec }\end{array}$ & $\begin{array}{c}\text { Flight path } \\
\text { angle. } \\
\text { deg }\end{array}$ & $\begin{array}{c}\text { Free-stream } \\
\text { Mach } \\
\text { number }\end{array}$ & $\begin{array}{c}\text { Vehicle } \\
\text { weight. } \\
\text { lbm }\end{array}$ \\
\hline Lift-off & 0 & 0 & 1.340 & 90 & 0 & 130,000 \\
\hline Mode 1-2 transition & $1: 07$ & $34.399 \mathrm{ft}$ & 3,321 & 12.9 & 2.04 & 94.630 \\
\hline Mode 3-4 transition & $5: 45$ & $126.704 \mathrm{ft}$ & 11.510 & 3.1 & 9.85 & 81.915 \\
\hline Begin coast & $8: 31$ & $45.02 \mathrm{nmi}$ & 26.018 & 1.6 & $\ldots$ & 28.926 \\
\hline Begin circ. bum & $39: 42$ & $221.60 \mathrm{nini}$ & 24.746 & 0 & $\ldots$ & 28,926 \\
\hline End circ. burn & $39: 48$ & $221.62 \mathrm{nmi}$ & 2.5 .146 & 0 & $\ldots$ & 28.138 \\
\hline
\end{tabular}




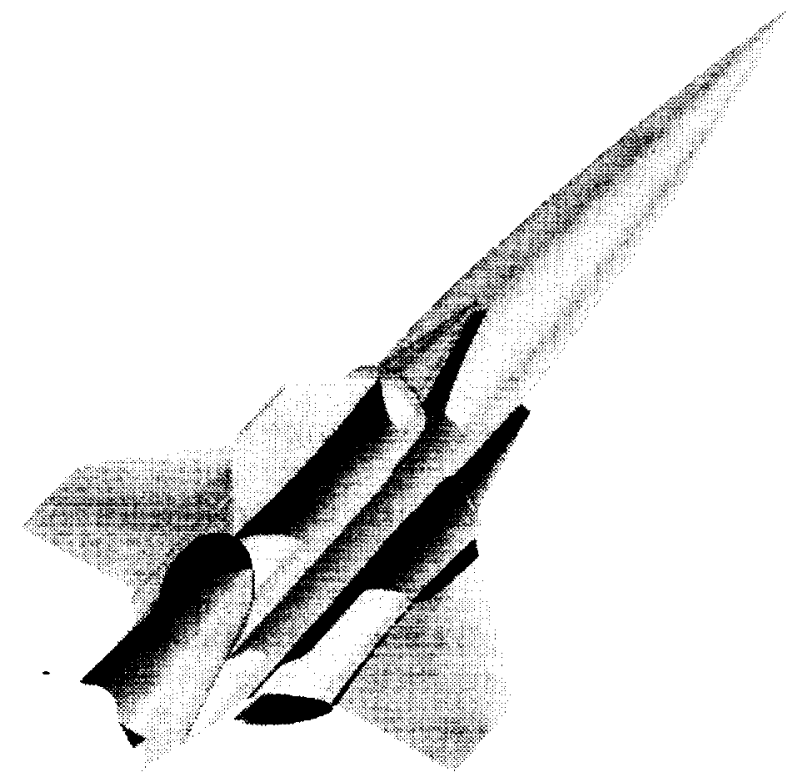

Figure 1.-Trailblazer reference vehicle.

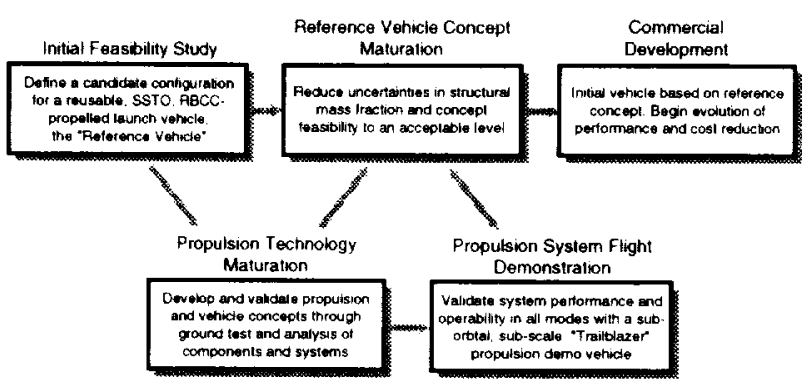

Figure 2.-Proposed program.

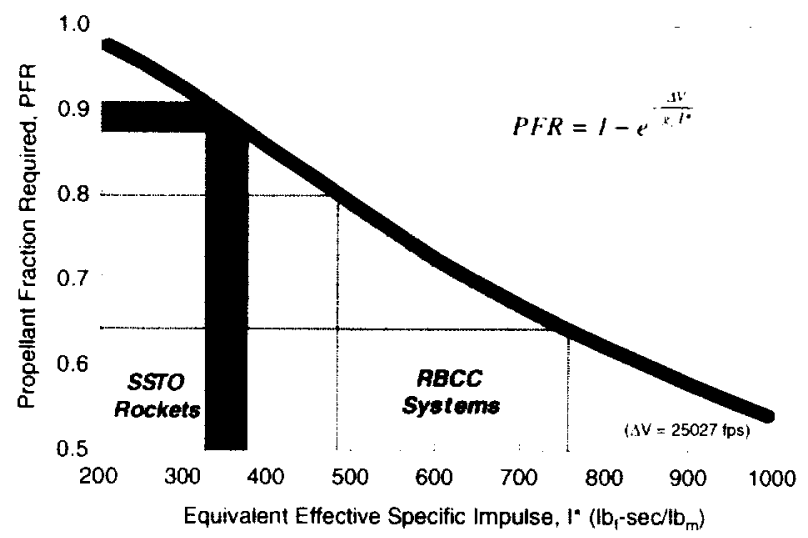

Figure 3.-Effect of $I^{\star}$ on propellant mass fraction for SSTO.

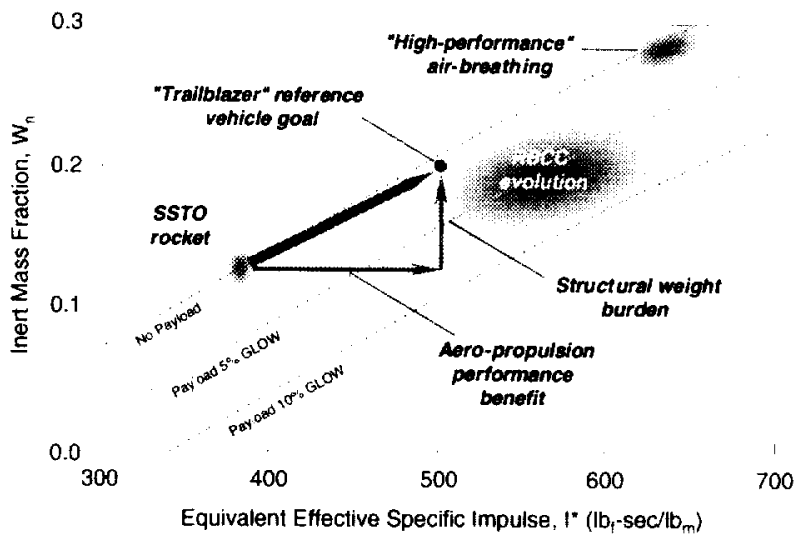

Figure 4.-SSTO launch vehicle design space.
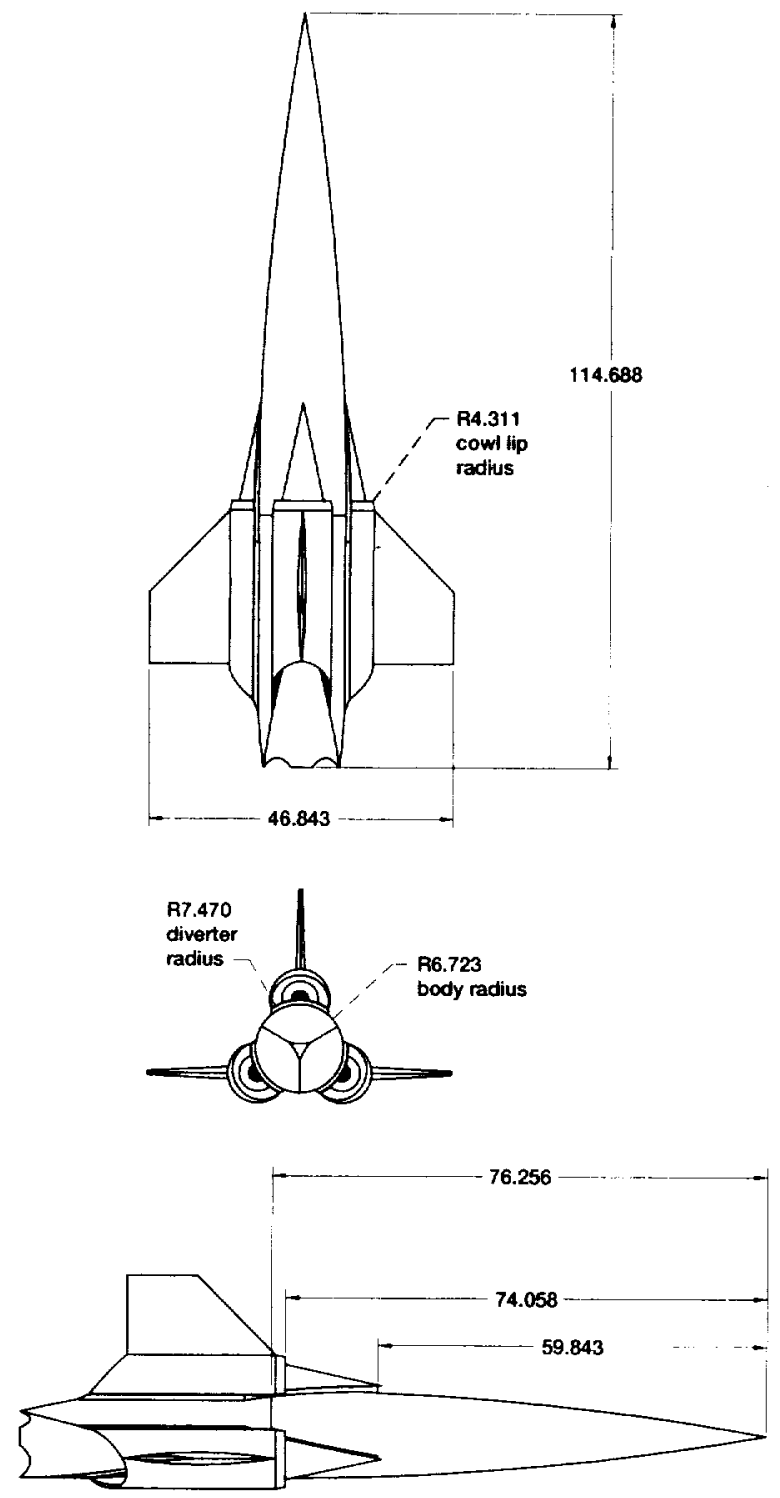

Dimensions in feet

Figure 5.-Reference vehicle geometry. 

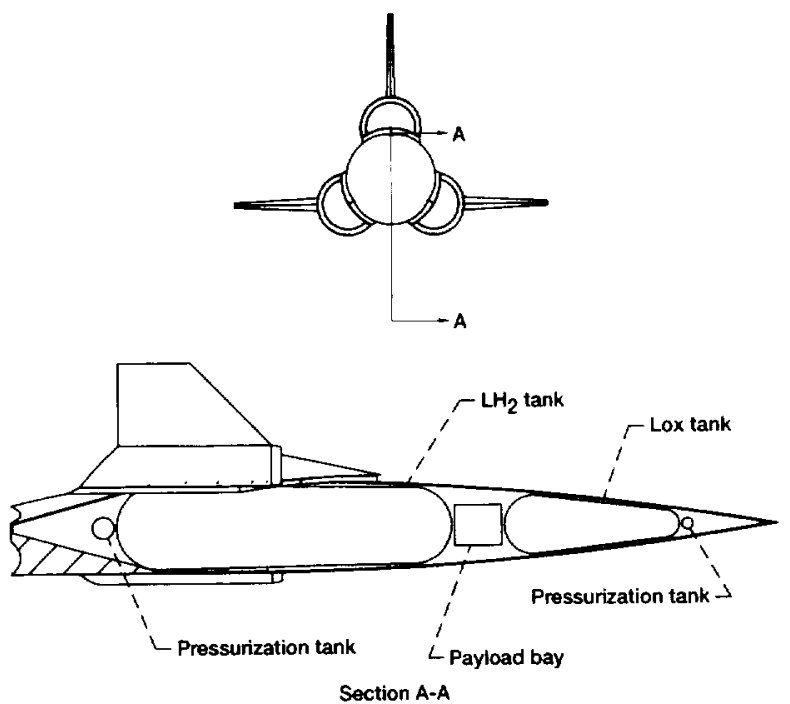

Figure 6.-Preliminary vehicle layout.

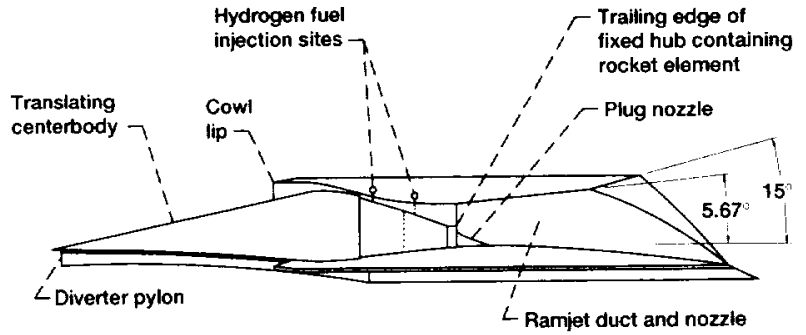

Figure 7.-Cut-away view of propulsion system.
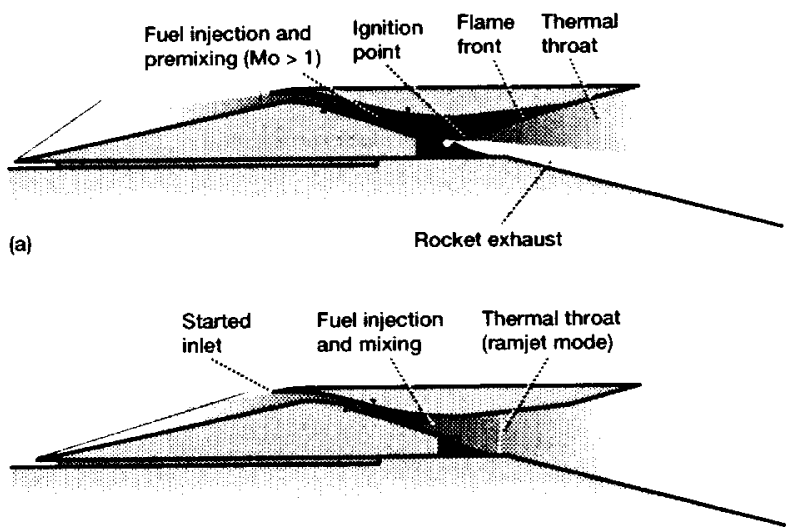

(b)

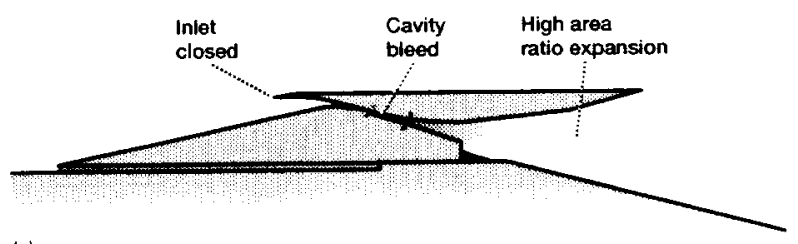

(c)

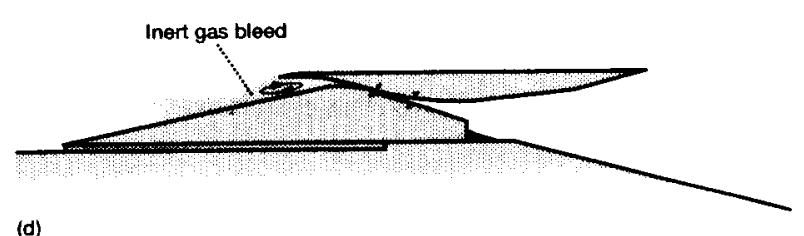

(d)

Figure 8.-Propulsion system operating modes.

(a) Mode I, lift-off and low speed. (b) Modes II and III, ram and scramjet. (c) Mode IV, rocket. (d) Re-entry concept. 


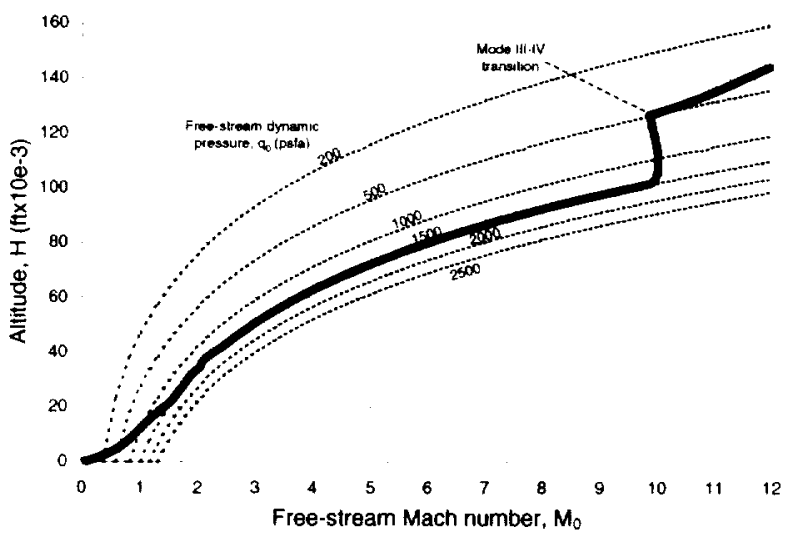

Figure 9.-Optimum trajectory.

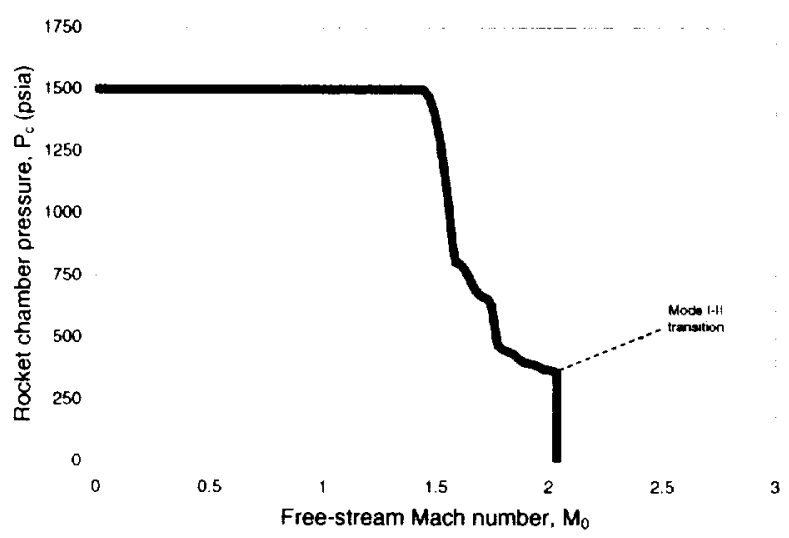

Figure 10.-Optimum chamber pressure schedule.

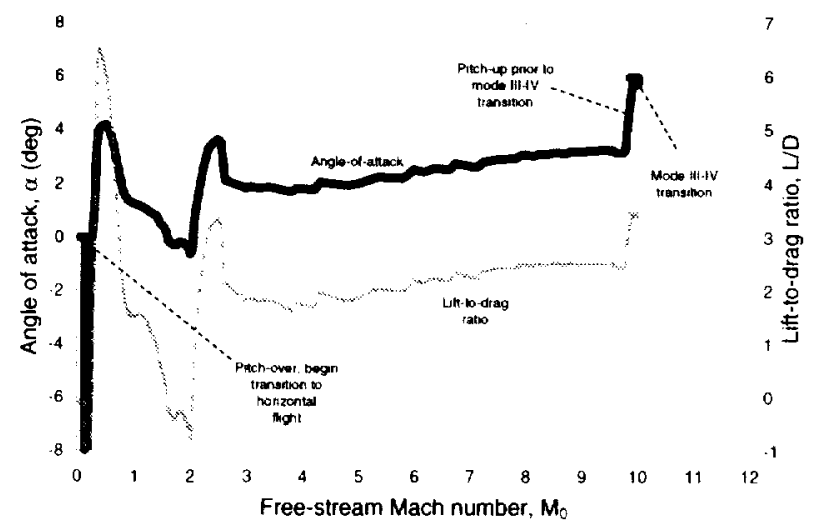

Figure 11.-Angle-of-attack and lift-to-drag ratio on optimum trajectory.

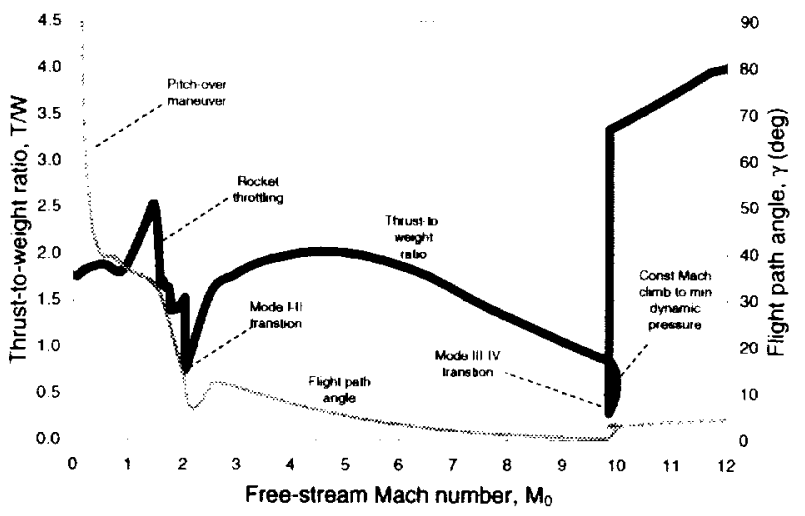

Figure 12.-Vehicle thrust-to-weight ratio and flight path angle on optimum trajectory.

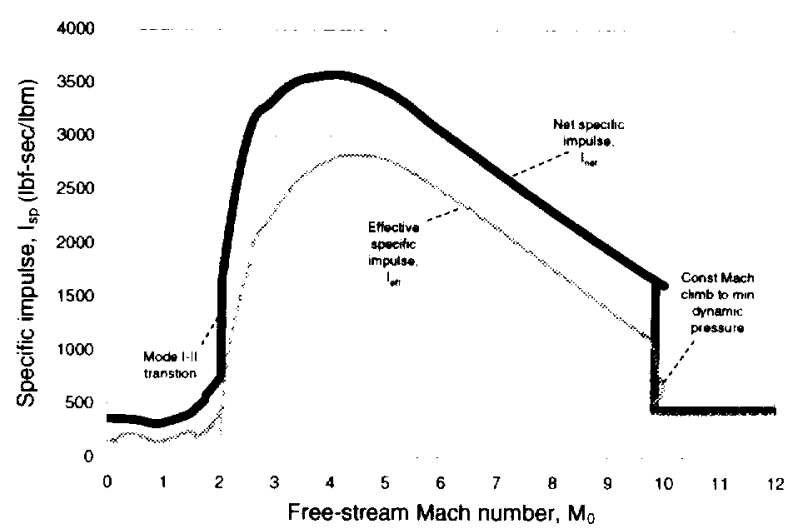

Figure 13.-Specific impulse on optimum trajectory. 
Public reporting burden for this collection of information is estimated to average 1 hour per response. including the time for reviewing instructions, searching existing data sources. gathering and maintaining the data needed. and completing and reviewing the collection of information. Send comments regarding this burden estimate or any other aspect of this Davis Highway, Suite 1204. Arlington, VA 22202-4302, and to the Office of Management and Budget. Paperwork Reduction Project (0704-0188). Washington. DC 20503.

\begin{tabular}{|l|l|l}
\hline 1. AGENCY USE ONLY (Leave blank) & $\begin{array}{c}\text { 2. REPORT DATE } \\
\text { May } 1999\end{array}$ & $\begin{array}{r}\text { 3. REPORT TYPE AND DATES COVERED } \\
\text { Technical Memorandum }\end{array}$
\end{tabular}

4. TITLE AND SUBTITLE

An Air-Breathing Launch Vehicle Concept for Single-Stage-to-Orbit

Charles J. Trefny

\section{PERFORMING ORGANIZATION NAME(S) AND ADDRESS(ES)}

National Aeronautics and Space Administration

John H. Glenn Research Center at Lewis Field

Cleveland, Ohio 44135-3191

\section{SPONSORING/MONITORING AGENCY NAME(S) AND ADDRESS(ES)}

National Aeronautics and Space Administration

Washington, DC 20546-0001

\section{FUNDING NUMBERS}

WU $-523-61-23-00$

8. PERForming ORGANIZATION REPORT NUMBER

$E-11674$

10. SPONSORINGMONITORING AGENCY REPORT NUMBER

NASA TM-1999-209089

AIAA-99-2730

11. SUPPLEMENTARY NOTES

Prepared for the 35th Joint Propulsion Conference and Exhibit cosponsored by the AIAA, ASME, SAE, ASEE, Los Angeles, California, June 20-23, 1999. Responsible person, Charles J. Trefny, organization code 5880, (216) 433-2162.

\section{2a. DISTRIBUTION/AVAILABILITY STATEMENT}

Unclassified - Unlimited

Subject Category: Categories: 15 and 20
Distribution: Nonstandard

12b. DISTRIBUTION CODE

This publication is available from the NASA Center for AeroSpace Information. (301) 621-0390.

\section{ABSTRACT (Maximum 200 words)}

The "Trailblazer" is a 300-lb payload, single-stage-to-orbit launch vehicle concept that uses air-breathing propulsion to reduce the required propellant fraction. The integration of air-breathing propulsion is done considering performance, structural and volumetric efficiency, complexity, and design risk. The resulting configuration is intended to be viable using near-term materials and structures. The aeropropulsion performance goal for the Trailblazer launch vehicle is an equivalent effective specific impulse $\left(I^{*}\right)$ of $500 \mathrm{sec}$. Preliminary analysis shows that this requires flight in the atmosphere to about Mach 10, and that the gross lift-off weight is $130,000 \mathrm{lb}$. The Trailblazer configuration and proposed propulsion system operating modes are described. Preliminary performancè results are presented, and key technical issues are highlighted. An overview of the proposed program plan is given.

14. SUBJECT TERMS

Reusable launch vehicles; Air breathing engines; Single phase to orbit vehicles

\section{SECURITY CLASSIFICATION OF REPORT}

Unclassified

18. SECURITY CLASSIFICATION
OF THIS PAGE
Unclassified

Unclassified
19. SECURITY CLASSIFICATION OF ABSTRACT

Unclassified 


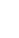

